\title{
TOWARD CIVILIZATION: How Can It Affect Music Education?
}

\author{
by Paul R. Lehman
}

he problem is [that] basic arts education does not exist in the United States today.

The arts are in triple jeopardy: They are not viewed as serious; knowledge itself is not viewed as a prime educational objective; and those who determine school curricula do not agree on what arts education is.

There is a major gap between the stated commitment and resources available to arts education and the actual practice of arts education in schools.

The single greatest drawback of existing arts curricula and the guides which teachers use is their emphasis on skill development at the expense of the art form as a whole.

It is fair to say that high school bands have probably done more than any other single institution to make live music a part of American life. ${ }^{1}$

Paul R. Lehman is MENC past-president and associate dean of the School of Music at the University of Michigan, Ann Arbor.
These excerpts are from Toward Civilization: A Report on Arts Education, published in March 1988 by the National Endowment for the Arts. The report was prepared in response to a congressional request for a study of the status of arts education; it is also intended as an "open letter to the American people, to the education community, and to those who love the arts and understand their importance in education."2

The report contains chapters on arts in the classroom, the arts curriculum, testing and evaluation in the arts, teachers of the arts, research in arts education, leadership in arts education, and the Endowment's role in arts education. The Endowment has attempted to identify the arts that should be taught in

\footnotetext{
1. Toward Civilization: A Report on Arts Education (Washington, DC: National Endowment for the Arts, 1988), 13, 19, 60, 75. Copies are available for $\$ 9.50$ each from the Superintendent of Documents, U.S. Government Printing Office, Washington, DC 20402.

2. Toward Civilization, 1-2
}

school, to present the reasons for studying them, to show why the present state of arts education is unsatisfactory, and to suggest ways it can be improved.

\section{Raising issues}

Most of the data are drawn from a survey of seven hundred school districts that was undertaken jointly by the Endowment and the United States Department of Education in 1987 and from Arts, Education, and the States, the 1985 survey of the Council of Chief State School Officers. The report also relies on a variety of other sources, including interviews, textbooks, curriculum guides, Educational Resources Information Center (ERIC) abstracts, and reports and recommendations from various sources, including MENC. The Endowment consulted the National Council on the Arts, and I served on an advisory committee organized specifically to provide guidance in the preparation of the report. 
Reproduced with permission of the National Endowment for the Arts, 1988

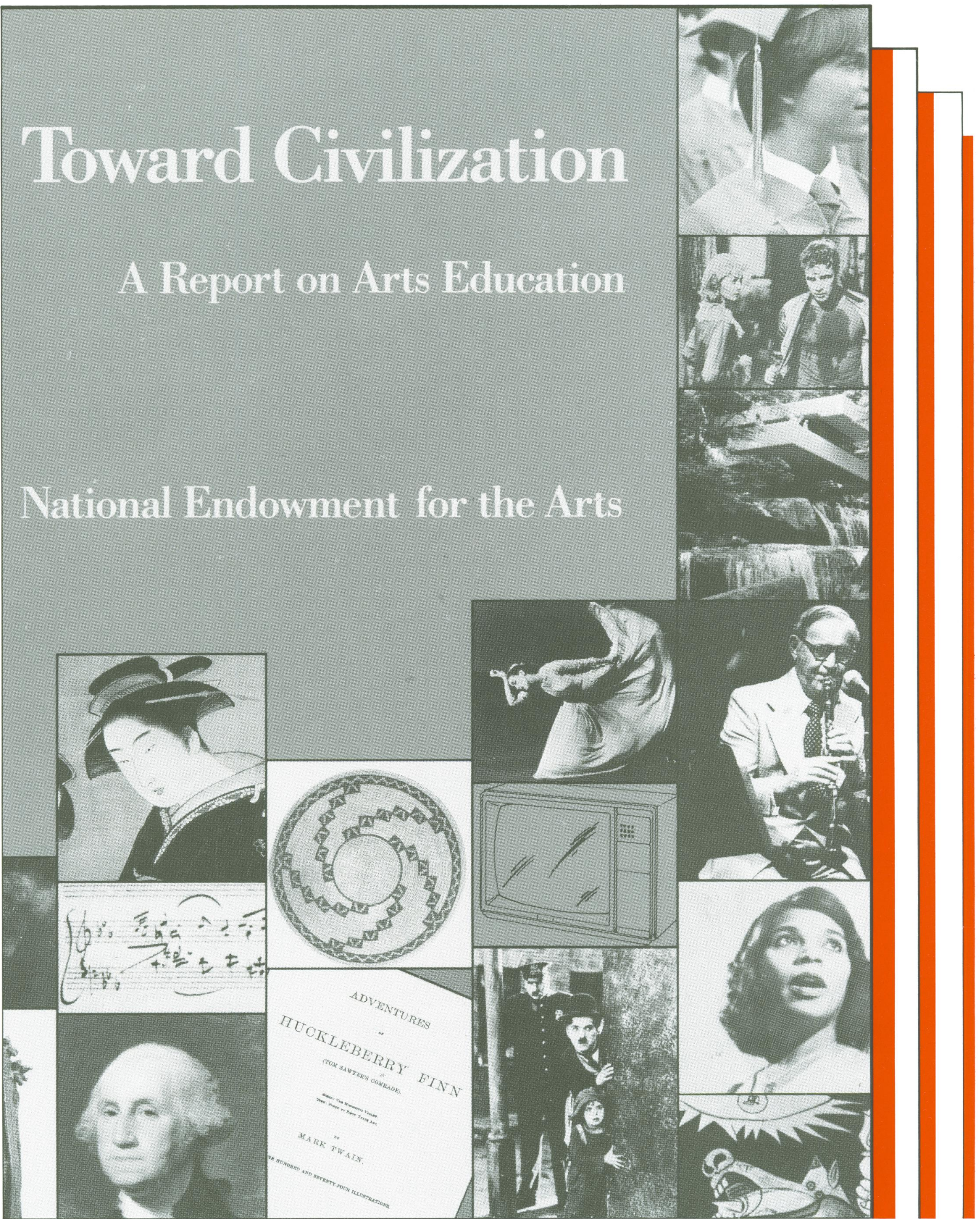


into his own thinking. He has not yet accepted my suggestion that the Endowment's Arts in Education Program should be administered as a challenge grant program and open only to schools with comprehensive programs in music and art, but, after all, there are many firmly entrenched, traditional groups whose views he must consider. After the final meeting of the advisory committee, I sent him a list of seven specific suggestions that I thought should be contained in the report. Six of them were included in one way or another. Not all appeared in the form I would prefer, but, nevertheless, I believe that Hodsoll has been very responsive to the concerns of the nation's music educators.

\section{The problem of breadth}

The most serious weakness of the report is that arts education is defined too broadly. According to the report, basic arts education includes literature and writing, visual art and design (including painting, sculpture, photography, video, crafts, architecture, landscape and interior design, stage design, and product and graphic design), performing arts (including dance, music, opera, theater, and musical theater), and media art (including film, television, and radio). The stunning breadth of this definition, which was forced on the Endowment by the legislation that created it, coupled with the premise that basic arts education must reach all children, not only explains but guarantees the Endowment's conclusion that "basic arts education does not exist in the United States today."

MENC defines the arts to include music, art, theater, and dance. Of course, there are other arts. In one sense, anything done well is an art. But it is unrealistic to think that schools are going to offer courses in all of the arts for which the Endowment assumes responsibility or that states are going to certify teachers in them. The problems caused by the Endowment's definition, already apparent in the report, become even more obvious when educators and administrators attempt to translate these generalized ideals into specific curricula.

The solution is for the Endowment to adopt a multilevel approach to its advocacy. It is fine to treat all of the arts identically in the abstract, but to get things done in the real world of education it will be necessary to employ strategies that are differentiated for the various arts. Music and art already exist in most schools. What music and art programs need is to be expanded, balanced, and strengthened. The cause of music and art cannot be advanced if education leaders persist in grouping them together with landscape design and architecture.

Relatively few schools recognize theater, dance, film, photography, and crafts as discrete disciplines. Achieving their widespread acceptance is a valid aim, but it will require different tactics from those used to promote music and art. In most schools, the remaining arts will have to be incorporated into courses devoted primarily to other disciplines or dealt with in other imaginative ways using yet another array of advocacy strategies. All of these fields need the Endowment's help, but they cannot all be promoted in the same manner. To be effective, we must focus our efforts where there is a reasonable chance of success; we must not dissipate our energies in struggles that cannot be won.

\section{A performing art}

In the section of Toward Civilization that includes the high school music curriculum, the Endowment alleges that there is a "performance bias." After reading the report, many music teachers will perceive a bias against performance hovering just below the surface. This antiperformance bias stems partly from the current controversy raging in visual arts education concerning so-called discipline-based arts education, partly from a tendency to forget that music is a performing art, and partly from a misunder- standing of the basis of curriculum construction.

Students in performing groups should learn the historical and theoretical bases of the repertoire they perform, but the primary reason students enroll in these groups is to perform. The content of elective courses is based not only on educational legitimacy but also on student interest. We definitely need more nonperformance offerings in secondary school music, especially in those states that require the arts for high school graduation. We also need to do a better job of teaching our diverse cultural heritage. We do not need to apologize, however, for having strong performance programs. There is no better way to learn music than through performance. Let's add to our performance offerings, not weaken them.

The report contains fifty-four recommendations. Several of them are strikingly similar to MENC's Goals for 1990 or to standards specified in The School Music Program: Description and Standards. The following are some major recommendations that are especially pertinent for music educators, with a few personal observations:

Arts education should provide all students with a sense of the arts in civilization, of creativity in the artistic process, of the vocabularies of artistic communication, and of the critical elements necessary to making informed choices about the products of the arts. ${ }^{3}$

The Endowment also recommends that state education agencies should put into place specific policies that make arts education a sequential part of the curriculum for all students $\mathrm{K}-12$. This recommendation constitutes another influential source of support for one of MENC's major goals. We should constantly bring these recommendations to the attention of superintendents and principals.

Toward Civilization contains a recommendation that elementary schools provide arts instruction for

3. Toward Civilization, 35 
approximately 15 percent of the school week. MENC has recommended that 7 to 9 percent of the instructional day in the elementary school should be devoted to music; the Endowment recommendation is consistent with this.

Junior high and middle schools (grades six through eight) should require all students to take arts instruction, exclusive of English studies, for at least 15 percent of the school year.... ${ }^{4}$

The language used in this recommendation is unfortunate because 15 percent of the school year does not have the same connotation as 15 percent of every student's curriculum. A five-week module of music represents 15 percent of the school year, but it does not provide the sustained exposure that MENC considers necessary. The Endowment's survey revealed that an average of 17 percent of the instructional time in grades seven and eight is currently devoted to the arts, ${ }^{5}$ a finding that may be at odds with the experience of many music teachers.

High schools should require all students satisfactorily to complete two full years (or two Carnegie units) involving the arts (not as an alternative to courses like foreign languages or computer sciences) in order to receive a graduation diploma.... This purpose might be achieved either through arts courses per se or through making the arts integral parts of other courses... [Schools] may also wish to consider a seven-period day in accommodating these and other increased requirements. ${ }^{6}$

Two years of the arts for every high school student goes beyond the MENC standard of one year, but it is consistent with John Goodlad's recommendation that the arts comprise 15 percent of the curriculum. ${ }^{7}$ Unfortunately, the Endowment's standard is flawed because it in-

\footnotetext{
4. Toward Civilization, 35.

5. Toward Civilization, 69

6. Toward Civilization, 36.

7. John Goodlad A Place Called School (New York: McGraw-Hill, 1983), 286-7.
}

cludes literature in its definition of the arts and is further undermined by allowing the requirement to be satisfied by "making the arts integral parts of other courses." In a few cases, like this, it may be better not to read the entire recommendation!

In referring to a seven-period day, the Endowment means at least seven periods. The Endowment does not recommend that any school reduce its school day to seven periods. The MENC standard also calls for at least seven or eight periods.

The report suggests that students in the arts should be tested to determine what they have learned and that arts education programs should be evaluated. These are issues that we as music educators must take much more seriously in the future if we want music to be accepted on an equal basis with other basic subjects. Despite its eloquent plea for effective program evaluation in the arts, however, the Endowment has thus far been unwilling to provide support for MENC's Program Evaluation Project, a massive effort to develop instruments for the comprehensive assessment of $\mathrm{K}-12$ music programs, even though the project is technically sound and is the only major effort of its kind in the nation.

The report also includes a recommendation that the U.S. Department of Education and the Endowment work together to restore assessments in art, music, and literature to the National Assessment of Educational Progress.

State certifying agencies should strengthen arts certification requirements for all teachers whose responsibilities include the arts. Training of all teachers elementary school classroom teachers, specialist arts teachers, and teachers of other subjects to which the arts are relevant-should include (i) study of important works of art (their craft, history, and significance to the civilizations which they symbolize) and (ii) study of techniques for creating or performing one of the arts.... For elementary school classroom teachers ... these requirements should include at least two courses in the arts which stress content. ${ }^{8}$

During the 1970s many teacher education institutions dropped or reduced their requirements in music and art for classroom teachers. It is time to reinstate these requirements, especially in those states where the bulk of music teaching is being done by classroom educators rather than music specialists.

Arts teachers, no less than teachers of other subjects, should be provided with opportunities to advance within their profession. State education agencies and school districts should develop standards and incentives to this end, and should promote career mobility within the school, district, region, or state. Such incentives should include full or partial reimbursement of expenses for summer studies and for attending professional meetings and conferences. ${ }^{9}$

Many schools not only have stopped paying teachers' expenses to attend in-service conferences; they have made it increasingly difficult for teachers to attend at their own expense. This attitude is shortsighted, counterproductive, and completely at odds with the spirit of educational reform. There is no better investment a school can make than to send its music teachers to professional conferences, such as MENC national, division, and state meetings.

Each school district should aim to provide arts instruction by trained arts specialists at all levels $\mathrm{K}-12 \ldots$ Elementary school administrators should recruit teacher curriculum coordinators for each of the arts. Where available, arts specialists should be given this responsibility; where they are not available, classroom teachers with particular interests and qualifications in the arts should serve as coordinators in the interim....10

\footnotetext{
8. Toward Civilization, 37

9. Toward Civilization, 39

10. Toward Civilization, 39.
} 
The MENC standards specify that music should be taught by music specialists, with their efforts complemented by classroom teachers. Furthermore, MENC specifies that one music educator in each school district should be designated as coordinator or administrator to provide leadership for the music program. This should be a full-time position when there are ten to fifteen music teachers, with the appointment fraction increased or decreased if there are more or fewer teachers.

The governance, education, arts and business-producer sectors should work together to convince parents and political and education leaders at the state, district, and local levels that education is complete and acceptable only when the arts are included as essential components sequentially taught.

The National Endowment for the Arts, which is to arts education what the National Science Foundation is to science education, should (i) make the case for arts education, (ii) facilitate collaboration among the four sectors concerned with arts education (governance, education, arts, business-producer) to make it a basic and sequential part of school instruction, and (iii) assist development and distribution of curricular, instructional, and assessment models for the benefit of state and local education authorities. ${ }^{11}$

The report correctly emphasizes the need for state and local arts agencies to work together with arts educators to promote arts education in the schools. As music educators we should take the initiative by proposing ways that these agencies and individuals can help overcome the barriers to strong music programs that exist in the state or community. We should cooperate fully with leaders in art, theater, and dance education at every opportunity. At the same time, we should recognize that music and art are much more favorably positioned in the schools than theater

11. Toward Civilization, 42-43 and dance. We should never pause in our efforts to advance music education while we wait for the other arts to catch up.

We should organize in each state a joint task force of leaders in the arts, arts education, the state arts agency, and the Alliance for Arts Education to implement those recommendations that are of common interest to us all. We should organize similar groups at the local level. The potential of those concerned with the arts in the private sector and the state and local arts agencies to promote arts education in the schools is almost totally unrealized.

\section{A new era of cooperation}

In 1986, the emphasis in the Endowment's Arts-in-Education Program changed dramatically from concentrating solely on placing artists-in-residence in schools to encouraging collaboration between state arts agencies and state education agencies. This change opened the door to a new era of cooperation between state arts agencies, education agencies, and music educators associations.

We must build alliances to be effective in the political arena. The state and local arts agencies can be powerful allies. In some states these agencies and the Alliance for Arts Education are already working effectively with music educators. In many states, however, these groups have ignored our work and pretended that there is no worthwhile arts education going on in the schools. Now the Endowment has called for their cooperation. Let us see if more of them will help do what must be done. In turn, we must demonstrate that we are competent, that our vision of music education is valid, and that we wish to cooperate.

Toward Civilization provides solid support for many of our basic beliefs and can help in achieving the goals of MENC. Some of its recommendations are more useful than others; all would have more impact if there were fewer of them. Nevertheless, we should identify those recommendations that can be helpful and bring them to the attention of school administrators, politicians, and other leaders at the local and state levels at every opportunity. We should acquaint our colleagues with the recommendations by quoting them in our state publications and at our state conferences. We should cite them in the media. We should point them out to our students' parents, to our support groups, and to the public at large.

This report has taken the Endowment much further into the domain of arts education than it has ever ventured before. It has also forced the Endowment to learn all it could about arts education; never before has the Endowment been so well informed on the topic.

The Endowment discovered that there are nearly as many music and art teachers in the United States as there are science teachers. It discovered the existence of music textbooks and curriculum guides, and it found that some of them are excellent. It discovered, I hope, that despite our many problems, music is widely taught across the nation and that in many schools it is taught superbly. This new knowledge can provide MENC with a solid basis for further improvement of the excellent working relationship we have developed in recent years with the Endowment. This may yet be the most enduring legacy of Toward Civilization.

\section{Suggested readings}

Arts, Education, and the States: A Survey of State Education Policies. Washington, DC: Council of Chief State School Officers, 1985.

"MENC Goals for 1990." In "Newsbrief," Music Educators Journal 71, no. 1, September 1984, 12.

Music 1971-79: Results from the Second National Music Assessment. Report No. 10-MU-01. Denver: National Assessment of Educational Progress, 1981.

The School Music Program: Description and Standards. 2d ed. Reston, VA: Music Educators National Conference, 1986. 